\title{
CLONING AND SEQUENCE ANALYSIS OF THE SPIKE GENE FROM SEVERAL FELINE CORONAVIRUSES
}

\author{
A. Paul Reed, Sharon Klepfer, Timothy Miller and Elaine Jones \\ Department of Molecular Biology \\ SmithKline Beecham Animal Health \\ P.O. Box 1539, L34 \\ King of Prussia, Pennsylvania 19406-0939
}

\begin{abstract}
The DNA sequence encoding the spike gene from the DF2 strain of Type II feline infectious peritonitis virus (FIPV), a temperature sensitive FIPV virus (TS-DF2) and an isolate of feline enteric coronavirus (FECV 1683) were determined. Comparison of the published WSU 1146 and DF2 FIPV S genes showed that the viruses shared a high degree of homology $(99.6 \%)$. Likewise, the S gene of the virulent DF2 FIPV virus was closely conserved to that isolated from the vaccine virus strain, TS-DF2 FIPV. In contrast, the FECV $S$ gene had numerous DNA and amino acid differences when compared to the virulent FIPV sequences. Sequence differences among the feline coronavirus isolates were localized to the amino-terminus region of the $\mathrm{S}$ gene.
\end{abstract}

\section{INTRODUCTION}

Feline Infectious Peritonitis Virus (FIPV) is a member of the coronavirus family. The virus contains three major structural proteins: $25-30 \mathrm{kD}$ matrix protein $(\mathrm{M}) ; 50 \mathrm{kD}$ nucleocapsid protein $(\mathrm{N})$; and the $200 \mathrm{kD}$ surface glycoprotein spike (S). The spike protrudes from the surface of the virus and is the principal target of serum neutralizing antibodies.

FIPV causes a complex and highly fatal disease in cats. Although the mechanism of pathogenesis is not well understood, FIPV is generally considered to cause an immune complex disease associated with high circulating antibody titers and deposition of antigenantibody complexes in many major organs $(1,2,3)$. Vaccination attempts have largely been unsuccessful since previous exposure to the virus is associated with accelerated death after challenge $(4,5,6,7)$. The spike protein appears sufficient to induce sensitization to the virus in that kittens immunized with vaccinia recombinants expressing the $S$ gene developed FIP disease and died more rapidly than non vaccinated animals following virulent FIPV challenge $(8,9)$.

Recently, a temperature sensitive FIPV (TS-DF2) vaccine has been developed which, when administered intranasally, is efficacious and safe upon FIPV challenge (10). This virus was derived from a virulent DF2 FIPV strain but differs in its temperature specificity, plaque size and structural protein expression (11). 
Cats are often infected with another related feline coronavirus, feline enteric coronavirus (FECV), which causes only mild enteritis following isolation. Although the pathogenicity of the two viruses is distinct, FECV shares serological identity with FIPV.

To determine if alterations in the spike genes of these viruses had occurred, gene amplification techniques were used to amplify, clone and DNA sequence the $S$ gene from the wild type DF2 FIPV strain, the temperature sensitive variant (TS-DF2) and FECV. Comparison of these $S$ genes with the published sequence of the virulent WSU 1146 FIPV spike suggests regions which could be used to develop a diagnostic assay to distinguish the viruses serologically.

\section{METHODS}

\section{Virus strains.}

Several feline coronavirus strains were used in this study: FECV 1683 and FIPV WSU 1146 (Washington State University) (12), wildtype DF2 FIPV virus (11) and TS-DF2 FIPV (11).

\section{RNA purification.}

Roller bottles of confluent NLFK cells were infected with a feline coronavirus at $\mathrm{MOI}=$ 0.1 in $50 \mathrm{ml}$ of BME supplemented with $2 \%$ FBS. DF2 infections were performed in serumfree medium. The virus was absorbed for 2 hours and then $250 \mathrm{ml}$ of growth medium (BME $+2 \%$ FBS) added. The cultures were monitored for cytopathic effect and typically harvested at 24 - 36 hours post-infection. Total cytoplasmic RNA was prepared from the infected monolayers by guanidine isothiocyanate extraction (13).

\section{Oligonucleotide Design and Synthesis.}

Oligonucleotides were designed from the published WSU 1146 S gene of 4500 nucleotides and contained restriction sites to facilitate cloning into the pBluescript vector (Stratagene). The primers were synthesized on an Applied Biosystem Model 380B DNA Synthesizer using the phosphoramidite method and gel purified prior to use.

\section{PCR Amplification.}

PCR amplified $S$ gene fragments were generated using the following procedure. $c D N A$ from total cellular RNA infected with a specific coronavirus $(1 \mu \mathrm{g})$ was first synthesized (14). Amplification of the cDNA was performed essentially according to the method of Saiki et al. (1985) (15) using the Taq polymerase. PCR products were analyzed by electrophoresis of $5.0 \mu \mathrm{l}$ of the reaction on a $1.2 \%$ agarose gel run $16-17$ hours. Bands were visualized by ethidium bromide staining the gel and fluorescence by UV irradiation at $256 \mathrm{~nm}$.

\section{DNA Sequencing and Analysis.}

DNA sequence was determined from overlapping cloned regions of the $S$ gene from each virus strain. Nested set deletions were prepared and the sequence determined from both strands using the chain termination method (16) (Lark Sequencing Technologies, Houston, TX). DNA sequence analysis was performed using Beckman Microgenie programs on an IBM Model PS2 Model 70 or the University of Wisconsin GCG package of programs (17). 


\section{RESULTS AND DISCUSSION}

The S genes from DF2, TS-DF2 and FECV were 4362 bp in length and encoded an open reading frame of $1454 \mathrm{aa}(160 \mathrm{kD}$ molecular weight). As predicted for a surface glycoprotein, all three $\mathrm{S}$ genes contained a signal sequence at the amino terminus, a $\mathrm{C}$ terminal transmembrane domain and multiple $\mathrm{N}$-glycosylation sites. Some of these potential $\mathrm{N}$-glycosylation sites are common to both viruses.

The S gene of DF2 FIPV shares $99.8 \%$ nucleotide homology and $99.6 \%$ amino acid homology with another virulent strain of Type II FIPV virus, WSU 1146. Interestingly, the DF2 S gene sequence contains 6 extra nucleotides (positions 351 - 356) when compared to the published WSU $1146 \mathrm{~S}$ gene sequence. These two additional amino acids at positions 119 and 120 increase the size of the DF2 spike gene to 1454 aa in contrast to 1452 aa of WSU 1146. Six other amino acids differed between these virulent Type II FIPV strains, four of which were located in the amino terminal half of the gene.

The TS-DF2 FIPV vaccine virus was derived after 99 passages in vitro and mutagenesis of the virulent DF2 strain. Comparison of the S genes from the parental DF2 and the temperature sensitive TS-DF2 vaccine strain did not reveal substantial differences. Eighteen nucleotide changes were observed ( $99.6 \%$ homology) which resulted in 13 amino acid differences ( $99.1 \%$ homology). Nine of these 13 changes were located in the amino terminus but were not clustered, making it difficult to identify a region which could be used to differentiate TS-DF2 from its progenitor, DF2. One change at nucleotide \#1346 alters the sequence from Asn-Ala-Thr to Asn-Thr-Thr but does not affect glycosylation. The overall conservation of $S$ sequence between these isolates suggests that these viruses are relatively stable and have not undergone recombination at this gene locus.

Although DF2 FIPV and FECV are serologically related, comparison of the $S$ genes showed 67 amino acid differences between them (94.3\% nucleotide homology, 95.4\% amino acid homology). FECV appears similar to DF2 in that its S gene contains the two additional amino acids at positions 119 and 120 missing from WSU 1146. The majority of sequence changes in FECV were localized to the amino terminus of the gene (50 amino acid differences in the region 1-748). In addition, significant differences exist between FECV and the FIPV strains in specific regions of the sequence, i.e. 400 - $450 \mathrm{bp}$, suggesting that may be feasible to generate diagnostic probes to distinguish these serologically related viruses.

Table 1. Feline coronavirus nucleotide and amino acid ${ }^{1}$ homology matrix comparison.

\begin{tabular}{lllll}
\hline & STRAIN & DF2 & TS-DF2 & FECV \\
\hline Nucleotide & & & & \\
& WSU 1146 & 99.8 & 99.8 & 94.3 \\
& DF2 & & 99.6 & 94.3 \\
& TS-DF2 & & & 94.1 \\
Amino Acid & & & & \\
& WSU 1146 & 99.6 & 99.5 & 95.5 \\
& DF2 & & 99.1 & 95.4 \\
& TS-DF2 & & & 95.3 \\
\hline
\end{tabular}

${ }^{1}$ Value represents percent amino acid identity (actual match) between strains. 
In general, spike genes of feline coronaviruses are highly conserved ( $>95.0 \%$ average amino acid homology). No clear differentiation between the $S$ genes of virulent FIPV strains (DF2 or WSU 1146) and an attenuated vaccine strain (TS-DF2) or avirulent enteric virus (FECV) could be made by this analysis. When compared to the serologically related porcine
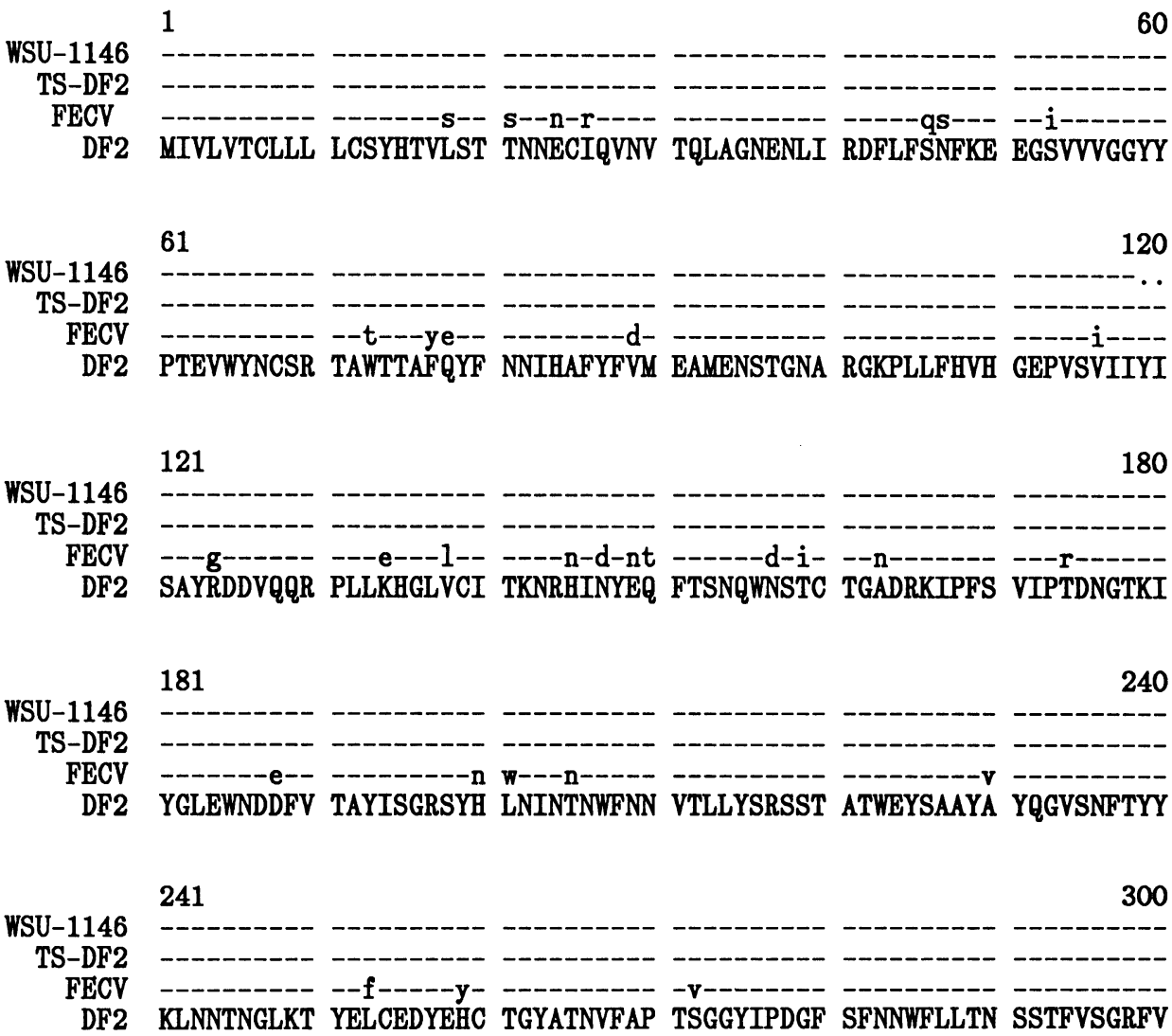

Figure 1. Comparison of the amino acid sequence of the first 300 aa of the $S$ gene from WSU 1146 (12), DF2 FIPV, TS-DF2 FIPV and FECV.

coronavirus, Transmissible Gastroenteritis virus (TGEV), the S genes of the DF2 FIPV and FECV feline coronaviruses were $82.0 \%$ homologous at the amino acid level (18). Not surprisingly, homology continued to decline as the feline $S$ genes were compared to those published from Mouse Hepatitis Virus (MHV-A59) and Avian Infectious Bronchitis Virus (IBV) $-29.2 \%$ and $30.7 \%$ amino acid homology, respectively $(19,20)$. 


\section{REFERENCES}

1. N.C. Pedersen and J.F. Boyle, Am. J. Vet. Res. 41:868-876 (1980).

2. H. Lutz, B. Hauser, and M.C. Horzinek, J. Small Animal Pract. 27:108 (1986).

3. N.C. Pedersen, Adv. Exp. Med. Biol. 218:529-550 (1987).

4. R.D. Woods and N.C. Pedersen, Vet. Microbiol. 4:11-16 (1979).

5. N.C. Pedersen and J.W. Black, Am. J. Vet. Res. 44:229-234 (1983).

6. C.A. Stoddart, J.E. Barlough, C.A. Baldwin and F.W. Scott, Res. Vet. Sci. 45:383-388 (1988).

7. J.E. Barlough. C.A. Stoddart, G.P. Jacobson and F.W. Scott, Lab. Anim. Sci. 34:592-597 (1984).

8. H. Vennema, R.J. De Groot, D.A. Harbour, M. Dalderup, T. Gruffyd-Jones, M.C. Horzinek and W.J.M. Spaan, J. Virol. 64:1407-1409 (1990).

9. H. Vennema, R.J. De Groot, D.A. Harbour, M.C. Horzinek and W.J.M. Spaan, Virology 181:327-335 (1991).

10. J.D. Gerber, J.D. Ingersoll, A.M. Gast, K.K. Christianson, N.L. Selzer, R.M. Landon, N.E. Pfeiffer, R.L. Sharpee and W.H. Beckenhauer, Vaccine 8:536-542 (1990).

11. K.K. Christianson, J.D. Ingersoll, R.M. Landon, N.E. Pfeiffer and J.D. Gerber, Arch. Virol. 109:185-196 (1989).

12. R.J. De Groot, J. Maduro, J.A. Lenstra, M.C. Horzinek, B.A.M. Van Der Zeijst and W.J.M. Spaan, J. Gen. Virol. 68:2639-2646 (1987).

13. J.M. Chirgwin, A.E. Przybyla, R.J. MacDonald and W.J. Rutter, Biochemistry 18:52945301 (1979).

14. E.S. Kawasaki. Amplification of RNA, in "PCR Protocols. A Guide to Methods and Applications," M.A. Innis, D.H. Gelfand, J.J. Sninsky and T.J. White, eds. Academic Press, San Diego, CA (1990).

15. R.K. Saiki, S. Scharf, F.A. Faloona, K.B. Mullis, G.T. Horn, H.A. Erlich and N. Arnheim, Science 230:1350-1354 (1985).

16. F. Sanger, S. Nicklen and A.R. Coulson, Proc. Natl. Acad. Sci. USA 74:5463-5467 (1977).

17. J. Devereux, P. Haberlie and O. Smithies, Nucleic Acids Research 12:387-395 (1984).

18. L. Jacobs, R.J. De Groot, M.C. Horzinek, B.A.M. Van der Zeijst and W.J.M. Spaan, (FIPV), Virus Res. 8:363-3712 (1987).

19. W. Luytjes, L.S. Sturman, P.J. Bredenbeek, J. Charite, B.A.M. Van Der Zeijst, M.C. Horzinek and W.J.M. Spaan, Virology 161:479-487 (1987).

21. J.G. Kusters, H.G.M. Niesters, J.A. Lenstra, M.C. Horzinek, and B.A.M. Van Der Zeijst, Virology 169:217-221 (1989). 